\title{
Visual Analysis of Twitter Data to Support Decision-Making in Law Enforcement: An Analytical Study of COVID-19
}

Prof.

Mamdooh Abdelhameed
Abdelmottlep*
Professor of Police
Administration and Law
Enforcement
Naïf Arab University for
Security Sciences
Saudi Arabia

Dr.

Muhammad Saifuddin Abdul Razzaq**

Assistant Professor of Criminal Policy and Law Enforcement

Naïf Arab University for Security Sciences Saudi Arabia

\section{Corresponding author:}

* Prof. Mamdooh A Abdelmottlep (Ph.D.), (SJD)

Professor of Police Administration \& Law Enforcement Naif Arab University for Security Sciences (NAUSS)

mabdelmottlep@nauss.edu.sa

USA: +18133369938 // Egypt: +201550513308// KSA: +966533143013

\section{The paper was coauthored by:}

** Dr. Muhammad Saifuddin Abdul Razzaq

Assistant Professor of Criminal Policy and Law Enforcement

Naïf Arab University for Security Sciences

M seif202020@yahoo.com

KSA + 966544718745

*** Dr. Yousra Hosny Abdelkhalek Hassaan

Associate Professor of Media

Assiut University and Imam Muhammad Ibn Saud University

yosrahossni@yahoo.com

Egypt: + 201021060820

\section{Acknowledgments:}

The Author would like to express his deep thanks to the Vice Presidency for Scientific Research at Naif Arab University for Security Sciences (NAUSS) for Their kind encouragement of this work.

\section{Funding:}

This work was supported by Security Research Center at Naif Arab University for Security

Ethics

Sciences (NAUSS) Contract Ref: (SRC-P19).

This article is original and contains unpublished material .

\section{Conflict of Interest}

The author declares that he has no conflict of interest. No ethical approval for this study is needed since it depends on the data deposited in the Twitter database. 